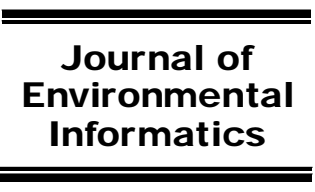

www.iseis.org/jei

\title{
A Study on Wetland Landscape Pattern and Its Change Process in Huang-Huai-Hai (3H) Area, China
}

\author{
A. N. $\mathrm{Li}^{1,4, *}$, W. Deng ${ }^{1}$, B. Kong ${ }^{1}$, X. N. Lu ${ }^{3}$, W. L. Feng ${ }^{3}$, G. B. Lei ${ }^{1}$, and J. H. Bai ${ }^{2}$ \\ ${ }^{1}$ Institute of Mountain Hazards and Environment, Chinese Academy of Sciences, Chengdu 610041, China \\ ${ }^{2}$ School of Environment, Beijing Normal University, Beijing 100875, China \\ ${ }^{3}$ Department of Environmental Engineering, Chengdu University of Information Technology, Chengdu 610225, China \\ ${ }^{4}$ Department of Geography, University of Maryland, College Park, MD 20742, USA
}

Received 7 January 2012; revised 25 December 2012; accepted 17 March 2013; published online 31 March 2013

\begin{abstract}
Wetland shrinkage and ecological function decline have become huge obstacles to regional and national sustainable development. In this paper, we comparatively analyzed three typical wetland ecosystems in the Huang-Huai-Hai (3H) Area, to clarify the similarities and differences of each pattern and their change process, as well as their intrinsic correlation mechanism. The satellite images were applied to construct the time-series wetland landscape maps in the last 30 years. Then landscape indices and information entropy metric were used to qualify the pattern and its change process respectively. The results showed that, the wetlands in $3 \mathrm{H}$ Area reached 32,632.9 $\mathrm{km}^{2}$ in 2000 , with the natural wetlands of $9,817.9 \mathrm{~km}^{2}$, occupying 2.21 percent of the whole $3 \mathrm{H}$ Area, lower than the average national level. In the last 30 years, the wetland area in $3 \mathrm{H}$ Area like all typical wetland subsystems decreased significantly, therein, natural wetland shrinking and artificial wetland increasing presented the different processes of wetland components and drive mechanisms, implying a complex ecological response to pattern evolution in $3 \mathrm{H}$ Area. The discussion on the driving forces system indicates that it is very necessary for the recovery and reconstruction of wetland system that regulates hydrological process in line with natural rules. It would provide possible measures to regulate and control the wetland ecosystem in $3 \mathrm{H}$ Area.
\end{abstract}

Keywords: Huang-Huai-Hai Area, pattern and process, landscape index, information entropy, remote sensing

\section{Introduction}

Wetlands are a special kind of ecosystems, known as "kidney of the earth", functioning ecologically, environmenttally and productively in the aspects of flood storage, climate regulation, pollution control, soil erosion reduction, landscaping, and maintenance of biological diversity and productivity (Ramsar Convention Secretariat, 2006). Some studies have shown that various types of ecosystems worldwide each year provide the service worthy of at least 33 trillion, including 4.9 trillion U.S. dollars from the wetlands (Costanza et al., 1997). According to U.S. scientists (El Serafy, 1998; Toman, 1998), each hectare of wetland each year can produce the value of 4 thousand to 14 thousand U.S. dollars or more, $2 \sim 7$ times more than tropical rain forests and $45 \sim 160$ times more than farmland ecosystems. However, in recent decades, wetland cultivation, pollution and overexploitation of resources have caused wetlands to become one of the most threatened global ecosystems. Since 1900, global wetland area has cut down 50 percent, currently accounting for about 6 percent of Earth's

${ }^{*}$ Corresponding author. Tel.: +86 28 85224131; fax: +86 2885222258.

E-mail address: ainongli@imde.ac.cn (A. N. Li).

ISSN: 1726-2135 print/1684-8799 online

(C) 2013 ISEIS All rights reserved. doi:10.3808/jei.201300229 land area (OECD, 1996). The conservation and wise use of wetlands has aroused the international concerns of wetland study groups, and has become one of the hot issues for global ecosystem studies.

The Huang-Huai-Hai $(3 \mathrm{H})$ area is an important grain production base, industrial core zone and densely inhabited area in China (Yang et al., 2006). The water space here takes on the unique spatial pattern of "three latitudinal and two longitudinal" water system, with the eastern and the middle routes of South- to-North Water Diversion Project (STNWDP) running cross the Huaihe River, Yellow River and Haihe River. It forms the wetland system composed of different components like rivers, lakes, marshes, estuaries, etc., and further becomes the vital center to maintain the life of the regional ecological environment (Yang et al., 2006). However, due to the rapid population growth and economic development in China, wetlands have reduced rapidly. The natural or semi-natural wetlands only account for 3.77 percent of total land area, far less than the world average level (6 percent). The $3 \mathrm{H}$ Area is now under the threat of intensified human activities, especially the agricultural development and rapid urbanization resulting in wetland shrinkage and degradation, serious shortage of wetlands water, the deterioration of water environment, serious damage to ecological functions of wetlands, biodiversity decline, and potential hydro-ecological crisis (Yang et al., 2006). 


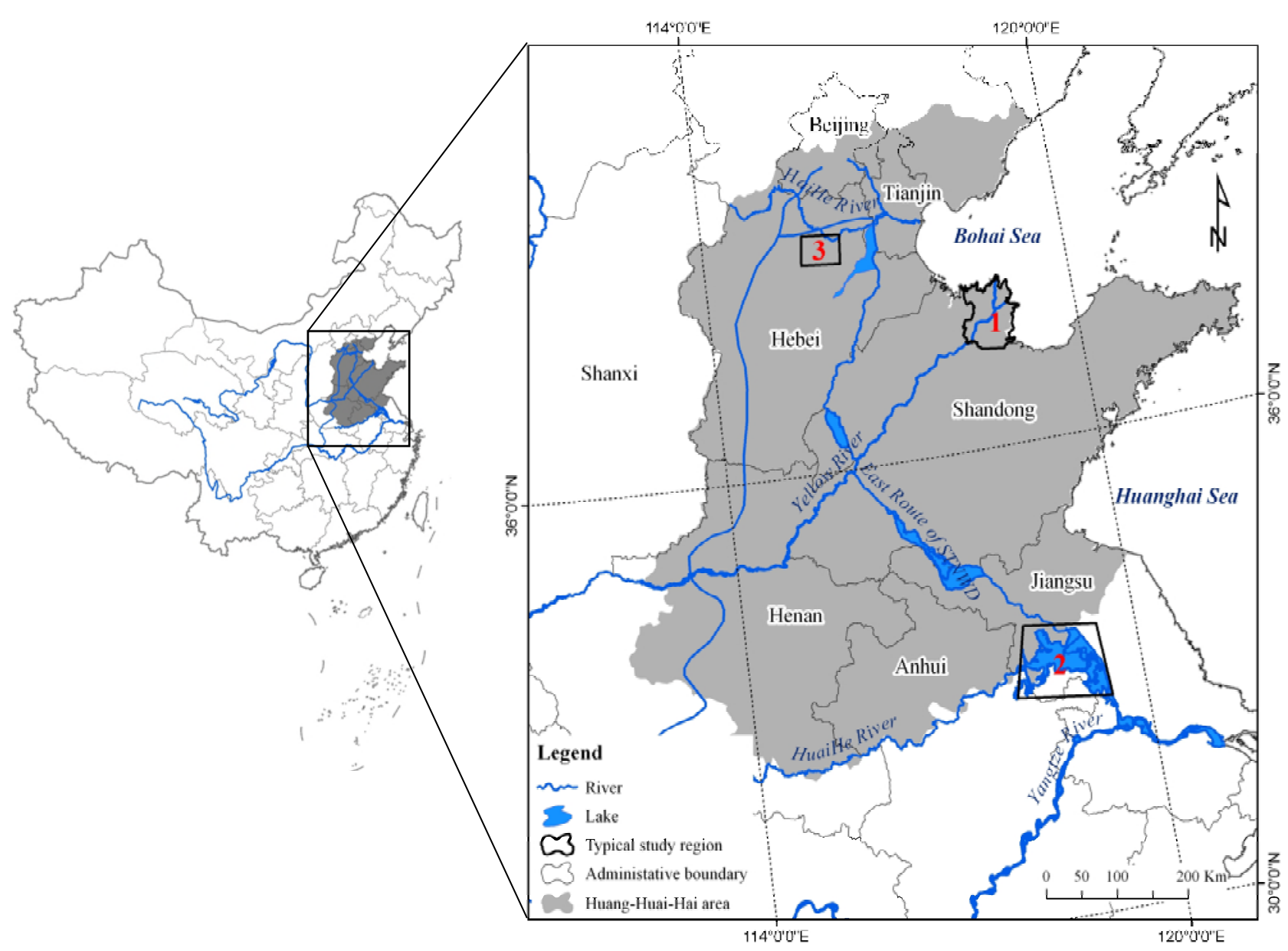

Figure 1. Geographic location and water spatial pattern of 3H Area in China, in which the bold boxes numbered 1, 2 and 3 , are the three sites of typical regions for the YRD, HGL and BLM wetland ecosystem respectively.

Apparently, dramatic changes have taken place on $3 \mathrm{H}$ wetland landscape in the last decades. It is very urgent for the government and scientific community to reveal the interaction and feedback mechanism among the different wetland components, and then to understand the overall pattern and its change of the wetland system in $3 \mathrm{H}$ Area. The formation of landscape pattern reflects the different landscape ecological process (Chen et al., 2006; Li et al., 2004; O'Neill et al., 1988; Tischendorf, 2001); meanwhile, the landscape pattern also to some extend affects the evolution process of landscape (He et al., 2000; Huang et al., 2003; Wang et al., 2001). The interaction between landscape pattern and ecological process has become the hot issue in the international study communities of landscape ecology (Baird et al., 2004; David and Thomas, 1998; Liu et al., 2003; Lu and Fu, 2001; Wu, 2000), and has become a key point for further studies (Deng and $\mathrm{Hu}, 2003$; Yang, 2002).

The objective of this study is to investigate the changes of wetland landscape pattern and their driving forces as well as the interaction between landscape pattern and ecological processes in the past 30 years in $3 \mathrm{H}$ Area. For such purposes, we selected the wetland system in the estuary of Yellow River Delta (YRD), Hongze-Gaoyou Lakes (HGL) and Baiyangdian
Lake-Marsh (BLM) as three typical regions, to analyze comparatively on the similarities, the differences and the inherent relevance among three major typical wetland systems in $3 \mathrm{H}$ Area. The totally six periods of remote sensing images (during 1970s 2000s) were utilized to interpret and obtain the chronological wetland system landscape patterns over the recent 30 years, and the landscape indices and information entropy were applied to quantify the spatial patterns and their change processes. The complex ecological response and driving mechanism of wetland pattern evolution were also discussed.

\section{Data and Methodology}

\subsection{Study Area}

Located at $110^{\circ} \sim 123^{\circ} \mathrm{E}$ and $32^{\circ} \sim 42^{\circ} \mathrm{N}$, the $3 \mathrm{H}$ Area is administratively comprised of most parts of Beijing, Tianjin, Hebei, Shandong, Henan, and the north of Jiangsu and Anhui province (Figure 1) with a total area of about $450,000 \mathrm{~km}^{2}$, which accounts for approximately 5 percent of the total national land area while its population accounts for 20 percent of total China, with a population density four times of the national average (Yang et al., 2006). The YRD estuary wet- 
Table 1. The Image Acquisition Dates and Features

\begin{tabular}{ll}
\hline Typical region & Data characteristic (acquisition year/sensor/spatial resolution) \\
\hline YRD & 1979/MSS/79 m; 1985, 1992, 1995, 2000, 2005/TM/30 m; 2008/Aero photo/<1 m; \\
HGL & 1979/MSS/79 m; 1985, 1995, 2000/TM/30 m; 2006/CBERS/19.5 m; 2008/Aero photo/<1 m; \\
BLM & 1979/MSS/79 m; 1985, 1995, 2000/TM/30 m; 2006/CBERS/19.5 m; 2008/Aero photo/<1 m; \\
\hline
\end{tabular}
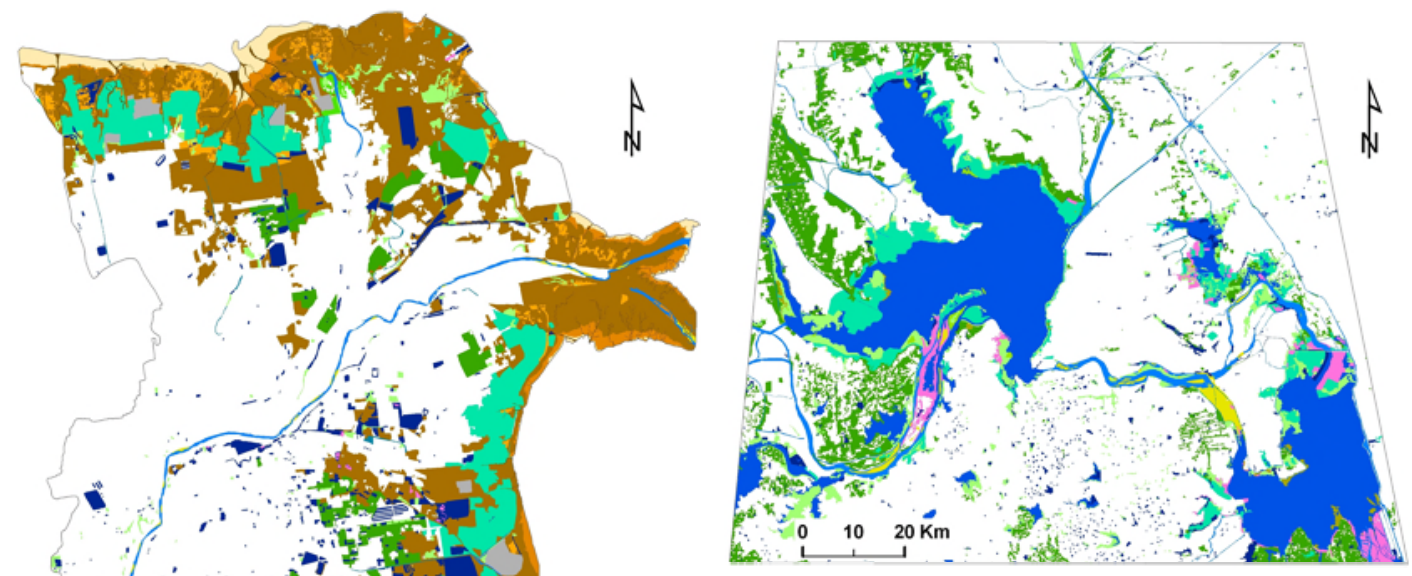

(a)

(b)

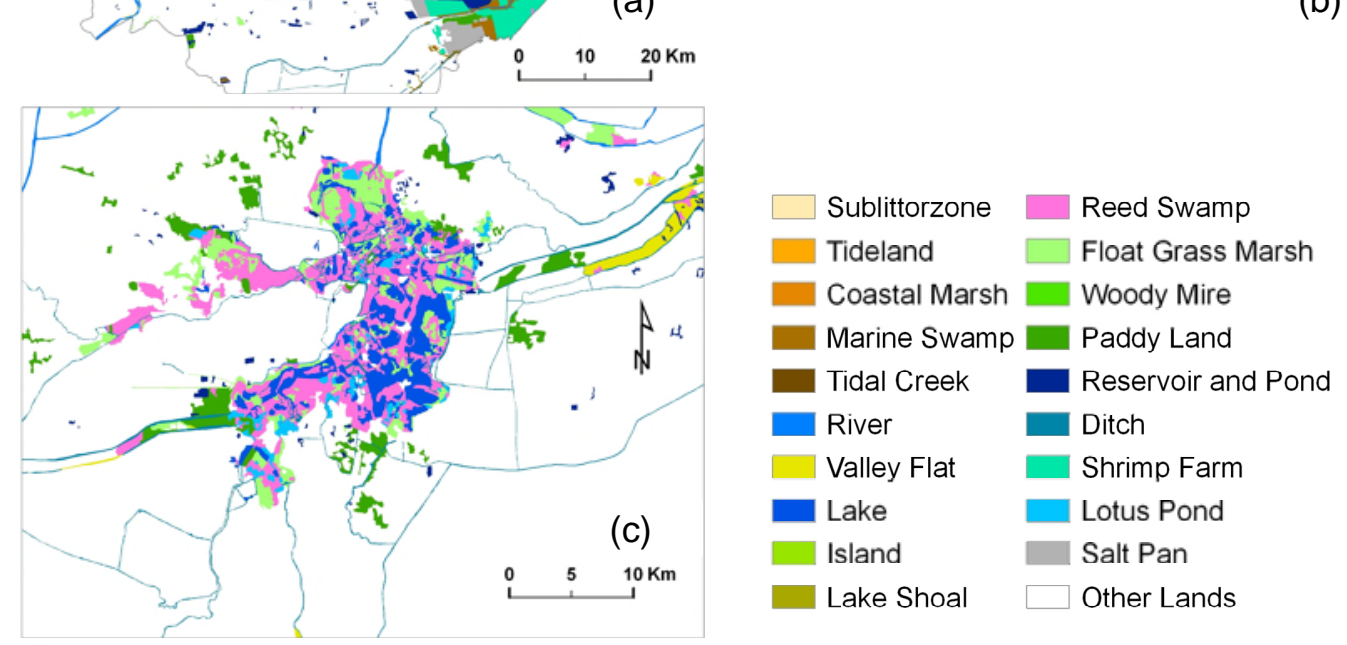

Figure 2. The current landscape pattern of three typical wetland systems, therein, (a) is for YRD in 2005, (b) for HGL and (c) for BLM in 2006.

land system, the HGL wetland system and the BLM wetland system, located in the lower reaches of the Yellow River, the middle and lower reaches of the Huaihe River, and the middle reaches of the Haihe River, respectively, are three typical representatives among the various sub-systems in the wetland systems of 3H Area (Figure 1).

Located in the warm temperate zone with a sub-humid climate, the $3 \mathrm{H}$ Area boasts sufficient sunshine and abundant heat resources with an annual precipitation of $400 \sim 1050 \mathrm{~mm}$ and an annual evaporation capacity of $897 \sim 913 \mathrm{~mm}$. Influenced by the pacific monsoon, the precipitation is subjected to an uneven spatial distribution and a more dramatic variation in yearly cycle. The $60 \sim 80$ percent of the precipitation in the whole year concentrates between June and September ( $\mathrm{Li}$ et al., 2008a). A shortage in water resources has become a key fac- tor for the restriction of the sustainable development of the agriculture and industry, and ecological water supply in $3 \mathrm{H}$ Area.

\subsection{Data Sources}

The logistical disadvantages of monitoring long-term vegetation community changes as well as evaluating an inaccessible area may be overcome by applying remote sensing techniques (Lee and Yeh, 2009). In view of the availability and cost, the remote sensing images from Landsat MSS, TM/ETM+ and the CBERS (launched by China in 1999) were acquired for wetland landscape retrieving (Table 1). The image acquisition date is required in vegetation growing season so that the different wetland vegetation types can be identified for various wetland patterns. 
All images were registered to the uniform geo-reference. Coordinate system is Albers Equal Area system with original longitude $103^{\circ} \mathrm{E}$, original latitude $0^{\circ}$, double-standard parallel of $27^{\circ} \mathrm{N}$ and $33^{\circ} \mathrm{N}$, Beijing1954 geodetic datum and Krassovsky ellipsoid. Landsat MSS, TM and CBERS images were used to interpret the wetland-vegetation landscape patterns, and aero photos acquired by unmanned aerial vehicle (UAV) in 2008 were applied as the high-resolution reference images for the accuracy testing and validation.

Based on the field data and the landscape data from $\mathrm{Hu}-$ man Computer Interaction interpretation on the basis of synthetic satellite images ( $\mathrm{Li}$ et al., 2010a), land cover maps have been compiled at the same scale to study the changes of landscape pattern. According to the Ramsar Convention on wetlands (Ramsar Convention Secretariat, 2006), and the wetland landscape characteristics of the 3H Area (Deng et al., 2010), landscape patterns in the delta were divided into 20 wetland types and several non-wetland types by a six-grade classification system. The wetlands are classified into littoral wetlands (sublittoralzone, tideland, tidal creek, coastal marsh (Tamarix), marine swamp (salt reed, suaeda glauca Bge), etc.), inland wetlands (river, flood plain, lake, island, lake shoal, reed swamp (aquatic plants), float grass marsh (floating plants), woody mire (willow), etc.), and artificial wetlands (paddy land, reservoir and pond, canal, ditch, artificial breeding pond (shrimp farm, crab field, fishpond and lotus pond.), salt pan, etc.)). The nonwetlands are classified into woodland, farmland, residential and construction land, unable land, etc. (Li et al., 2010a). This classification system can be compared with the existing systems and can be converted into each other through reasonable combination. Landscape types and their distribution in three typical regions are shown in Figure 2. The accuracy validation demonstrates that the overall mapping accuracy for three typical regions in 3H Area reaches 90.19 percent, with Kappa coefficient of 0.8563 ( $\mathrm{Li}$ et al., 2010a), which testifies that the wetland mapping in this study is credible, and meets the needs of spatial pattern analysis for $3 \mathrm{H}$ wetland system.

\subsection{Landscape Pattern Analysis Method}

\subsubsection{Landscape Indices Selection}

Landscape pattern reflects the spatial difference and correlation among various ecological systems, and is subjected to a continuous change along with the external disturbance, the internal evolution and renewal of the ecological system (Turner, 1990).

The landscape indices are constantly adopted in the landscape ecology to show the pattern and process of the landscape changes in a quantitative way (Turner and Gardner, 1991). At present, a lot of available landscape indices quantify the spatial feathers at the patch level, the class level and the land level respectively, including metrics of the area, density and edge, the shape, the contagion, the connectivity and diversity (O'Neill et al., 1988). Multiple indices are provided for each level and each metric, and a lot of correlation and information redundancy usually exist between each index (Bu et al., 2005). By comparing, Patch Density (PD), Perimeter-Area Fractal Dimension
(PAFRAC), Patch Cohesion Index (COHESION) and Aggregation Index (AI) were selected for the class level in this study. Besides the indices selected at the class level, Shannon's Diversity Index (SHDI) was also selected as the representative landscape index at the land level. All indices were acquired through the Spatial Analysis Module under the GIS software ArcView and the software Fragstats3.3.

\subsubsection{The Change Process Analysis of Landscape Pattern}

The analysis of the pattern by means of multiple indices is subjected to a complex result without the solid physical foundation, which has always been a hard issue in landscape ecology (Bai et al., 2005; Gustafson, 1998). Besides the single index analysis, this paper also utilized the information entropy to quantify the variation of the landscape indices along with the time axis. Information-theoretic quantities (e.g., entropy information) have been used by many researches as an alternative measure of dispersion (BarIlan, 2008; Jenssen, 2007). According to Shannon entropy (Shannon, 1948), the index $C$ is defined as below:

$$
C=-\sum_{i=1}^{m}\left(p_{i} \times \ln \left(p_{i}\right)\right) \text {, therein } p_{i}=x_{i} / \sum_{i=1}^{m} x_{i}
$$

where $C$ refers to the information entropy of $m$ landscape indices $x_{i}, p_{i}$ refers to the contribution of $x_{i}$ in all $m$ indices. Obviously, $C$ has no dimension, which can be considered as the integrated information of all $m$ landscape indices, and can be compared with each other.

The whole analysis includes three steps. Firstly, at land level, we selected five landscape indices (including PD, PAF RAC, COHESION, AI and SHDI) to qualify the total spatial pattern of each typical wetland ecosystem. Here $C$ was calculated as the integrated index that integrated total five different type indices $x_{i}$ for each year, therefore, the time series $C$ can refer to the integrated change process of wetland landscape patterns. Then, at class level, we selected four landscape indices (including PD, PAFRAC, COHESION and AI). For each wetland component, $C$ was used to calculate the variation information along time axis for each class level index. Here, $C$ denoted the contribution of each wetland component to the overall spatial pattern evolution. Large value of entropy implies more complexity/disorder in time series variables (Brunsell, 2010; Mishra et al., 2009), while disorderly time series component normally is considered to contribute less to the whole pattern evolution (BarIlan, 2008). The class level indices of those components with the smallest $C$ values were selected to participate in the change process analysis. Finally, using the selected class level landscape indices according to index $C$, the quantitative relations between component indices and whole landscape pattern were developed by stepwise regression method, which would accept or reject independent variable according to the statistical significance of each independent variable (Hocking, 1976). The accepted indices and components can be considered as the significant components, which will be used to analyze how the 
Table 2. The Area of Each Wetland Type and its Dynamic in Whole 3H Area during 1985-2000 (unit: km²)

\begin{tabular}{llllllll}
\hline Class & Paddy Land & Reservoir & River & Lake & Marine Marsh & Flood Plain & Marshland \\
\hline 1985 & 18071.2 & 4058.9 & 3710.0 & 1119.6 & 404.4 & 4498.5 & 1044.6 \\
2000 & 17932.2 & 4882.9 & 3500.8 & 1486.0 & 374.8 & 4014.6 & 441.7 \\
Changes & -139.0 & 824.0 & -209.2 & 366.4 & -29.6 & -483.9 & -602.9 \\
\hline Category & Artificial Wetlands & Natural Wetlands & & & \\
\hline 1985 & 22130.1 & 10777.1 & & & \\
2000 & 22815.1 & 9817.9 & & & \\
Changes & 685.0 & -959.2 & & & \\
\hline
\end{tabular}
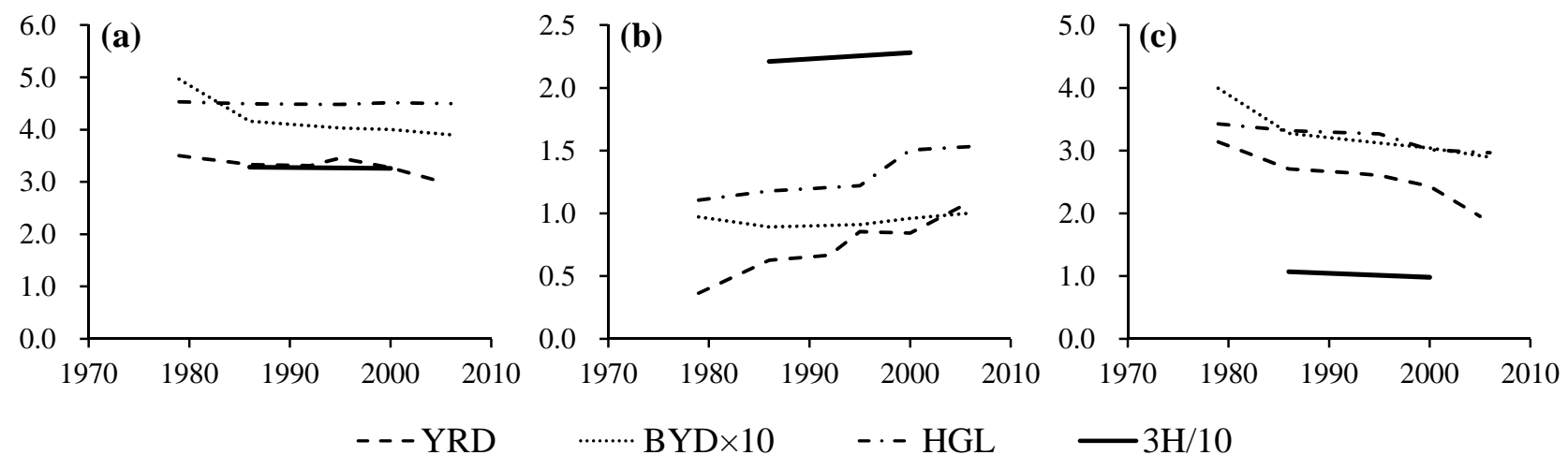

Figure 3. The area (unit: $\mathrm{km}^{2}$ ) change trends of each component for whole $3 \mathrm{H}$ Area and each typical study region, in which (a) is for total wetlands, (b) for artificial wetlands and (c) for natural wetlands.

variation at the class level drives the variation of the landscape pattern at the land level.

\section{Results Analysis}

\subsection{Overall Wetland Spatial Pattern and Its Change Process in $3 \mathrm{H}$ Area}

The wetlands in $3 \mathrm{H}$ Area reached $32,632.9 \mathrm{~km}^{2}$ in 2000 , with the natural wetlands of $9,817.9 \mathrm{~km}^{2}$ (Table 2). It includes rivers, lakes, marine marshes, flood plain and marshland, occupying 2.21 percent of the whole $3 \mathrm{H}$ Area, lower than the average national level (3.77 percent) (Yang et al. 2006). The area of artificial wetlands is approximate $22,815.1 \mathrm{~km}^{2}$ including paddy lands and reservoir ponds, and the area of paddy lands is $17,932.2 \mathrm{~km}^{2}, 78.51$ percent of total artificial wetlands. The whole wetlands have decreased $274.2 \mathrm{~km}^{2}$ in 15 years compared with that of the year 1985, in which the natural wetlands decreased more than $959.2 \mathrm{~km}^{2}$. It is mainly caused by the decrease of river, flood plain and marsh land. The artificial wetlands have increased $685.0 \mathrm{~km}^{2}$, in which reservoir pond increased $824.0 \mathrm{~km}^{2}$ and paddy field decreased $139.0 \mathrm{~km}^{2}$ (Table 2). It shows that the landscape change may affect the balance between ecologically sustainable water supply and water demand by ecosystems (Cai et al. 2011b). During 1985 $\sim 2000$, a large amount of reservoir ponds had been built, as a result of the increasing of water demand of industrial and agricultural production as well as domestic and ecological supply. However, on the other hand, the supply-demand inconsistency of water impelled many paddy fields to change into dry land to reduce the water supply in agricultural production.
Overall, the wetland changing tendencies of the three typical study regions are in conformity with that of the whole $3 \mathrm{H}$ Area in the last three decades (Figure 3). The artificial wetlands take on an increasing tendency while the natural wetlands present a decreasing tendency (Figure $3 \mathrm{~b}$ and c). Thus the whole wetlands mentioned above all take on a decreasing tendency though a slight difference occurs in the changing process (Figure 3a), which also verifies that the selected three typical areas are not only the representative of wetland types, but also are consistent in the changing characteristics with the whole $3 \mathrm{H}$ Area. The analysis of the wetland pattern and process of the typical areas reflects the overall characteristics and rules of wetland pattern and process of the whole $3 \mathrm{H}$ Area.

\subsection{Landscape Pattern and Its Change Process of in Three Typical Wetland Ecosystems}

\subsubsection{Landscape Indices}

The overall patch density of wetlands in the study area is relatively low (Figure 4a). The PD of BLM wetland (average $0.37)$ is the biggest, followed by that of the YRD $(0.25)$ and HGL (0.18). This means the patches in BLM system is the most broken one with the highest utilized degree, and that of HGL wetland is the most unbroken. The PD of the YRD wetland has an obvious rising tendency, which means the disturbance on it has a strengthening tendency in which a turning point appears in 2001. The PD series of the other two wetland-systems have slight changes, but its overall changing tendency is not obvious.

The fractal analysis mainly analyzes the broken degree of 

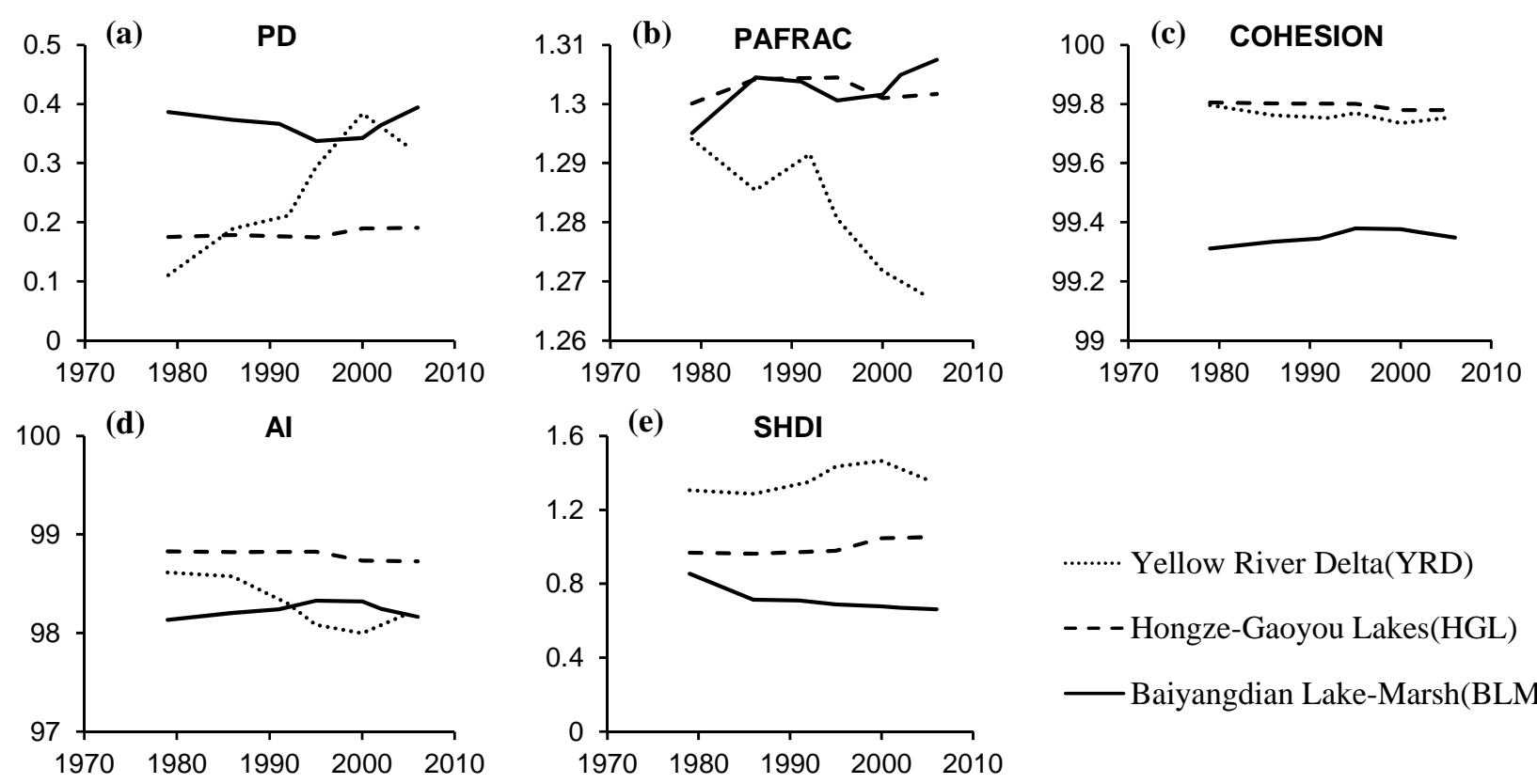

….... Yellow River Delta(YRD)

- - - Hongze-Gaoyou Lakes(HGL)

Baiyangdian Lake-Marsh(BLM)

Figure 4. Landscape indices and their processes for each typical wetland systems, in which (a) is for path density (PD), (b) for shape fractal dimension index (PAFRAC), (c) for patch cohesion index (COHESION), (d) for patch aggregation index (AI) and (e) for patch diversity index (SHDI).

landscape. However, the fractal dimension depends closely on data dimension, and has some restrictions on both scopes and numbers of patches. The three typical wetland systems in the study area are not complicated in shape, and among them the PAFRACs of BLM and HGL wetland system are almost exactly the same (about 1.30), and there are slight but not obvious changes (Figure $4 \mathrm{~b}$ ). That (1.28) of the YRD wetland is lower, and has an obvious tendency of decreasing in the past 30 years, which means the disturbance on it is rising continuously.

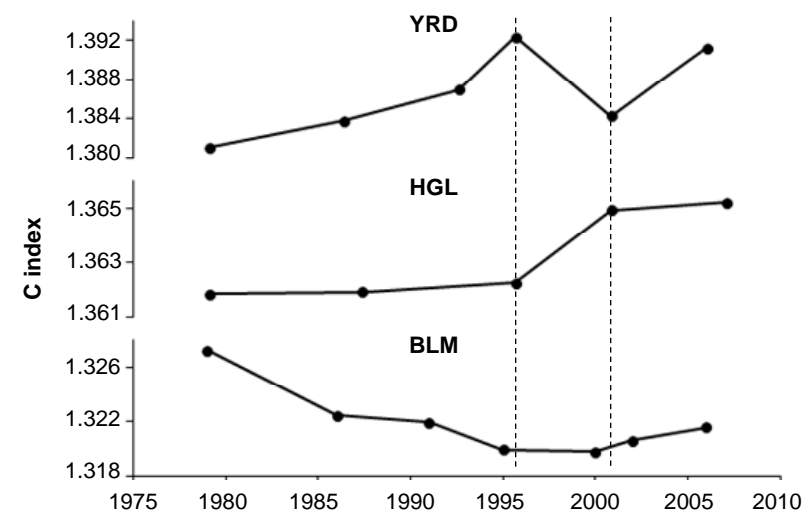

Figure 5. The distribution of index $\mathrm{C}$ in three typical regions along time axis.

Patch cohesion index quantifies natural cohesion ability of corresponding landscape type. The overall cohesion ability among wetland types is rather high (> 99.35), and has no obvious change, which means the cohesion ability between wetland patches is good and the material and energy can be transferred among different landscapes rather smoothly
(Figure 4c). It is determined by the natural property of wetland landscape because the wetland can transfer material and energy through water.

The overall aggregation ability of wetland patches is rather high (> 98.23), in which the HGL wetland almost remains steady and has the biggest aggregation ability. The YRD wetland has an obvious decreasing tendency after 1986, and gets to the bottom in 2001, and the BLM wetland has a rising tendency but a turning point appears in 2001 (Figure 4d).

SHDI refers to the measurement based on information theory, which is extensively used in bionomics. Heterogeneity of wetland landscape in the YRD is relatively high (1.37), and the increasing trend is obvious (Figure 4e). In a similar way, the inflection point of decline takes place in 2001, which indicates that landscape diversity of wetland system in YRD has been developing all the time. However, the significant factors of reversion appeared around 2001. Landscape of wetland system in HGL takes the second place (1.00), for which the inflection point of ascending appears around 1996. SHDI of BLM wetland is the lowest one (0.71) and the descending trend is continuing, which shows that BLM wetland is strongly disturbed by anthropological utilization, whose lake-marsh ecosystem diversity suffers from breakage.

\subsection{2. $C$ Index}

At the land level, each landscape index describes the spatial pattern feature and the development trend of three typical wetland subsystems from different views. All landscape indices represent the same changing trends and details, and the index $C$ integrates and confirms such change trends (Figure 5). The YRD wetland is the youngest estuary delta which is deve- 
Table 3. The Selected Landscape Indices in Class Level according to C Value in Each Typical Wetland Ecosystems

\begin{tabular}{llll}
\hline Index & YRD & HGL & BLM \\
\hline PD & Tideland, river, coastal marsh & Breeding pond, lake shoal, lake & Valley flat, river, float grass marsh \\
PAFRAC & Ditch, marine swamp, tideland & Valley flat, lake shoal, island & Reservoir, lake, reed marsh \\
COHESION & Breeding pond, reservoir, marine swamp & Breeding pond, reservoir, island & Reservoir, lotus pond, river \\
AI & Tidal creek, tideland, & Valley flat, reservoir, & River, reservoir, lotus pond \\
& Breeding pond & Breeding pond & \\
\hline
\end{tabular}

Table 4. The Stepwise Regression Equations between Land Level Pattern and Class Level Landscape Indices

\begin{tabular}{|c|c|c|}
\hline Regions & Stepwise Regression Equations & Selected Variables \\
\hline YRD & $\begin{aligned} y= & 1.53 x_{1}-10.441 x_{2}-0.174 x_{3} \\
& -0.002 x_{4}+0.001 x_{5}+1.485\end{aligned}$ & $\begin{array}{l}\mathrm{x}_{1}, \mathrm{PD} \text { of river; } \mathrm{x}_{2} \text {, PD of coastal marsh; } \mathrm{x}_{3} \text {, PAFRAC of tideland; } \mathrm{x}_{4} \text {, AI of } \\
\text { tideland; } \mathrm{x}_{5} \text {, AI of breeding pond }\end{array}$ \\
\hline HGL & $\begin{aligned} y= & -0.217 x_{1}+0.174 x_{2}-0.011 x_{3} \\
& +0.002 x_{4}+0.966\end{aligned}$ & $\begin{array}{l}x_{1} \text {, PD of lake shoal; } x_{2} \text {, PD of lake; } x_{3} \text {, PAFRAC of island; } x_{4} \text {, AI of breeding } \\
\text { pond }\end{array}$ \\
\hline BLM & $\begin{aligned} \mathrm{y}= & 0.287 \mathrm{x}_{1}+0.08 \mathrm{x}_{2}-0.08 \mathrm{x}_{3}-0.029 \mathrm{x}_{4} \\
& +0.002 \mathrm{x}_{5}-0.001 \mathrm{x}_{6}+1.098\end{aligned}$ & $\begin{array}{l}x_{1} \text {, PD of valley flat; } x_{2}, \text { PD of float grass marsh; } x_{3}, \text { PAFRAC of lake; } x_{4} \text {, } \\
\text { PAFRAC of reed marsh; } x_{5} \text {, COHESION of reservoir; } x_{6} \text {, AI of lotus pond }\end{array}$ \\
\hline
\end{tabular}

loping all the time, and tempestuous change has happened to its landscape pattern in the past 30 years, and the natural ecosystem has been deteriorating but one deflection point took place around 2001 (Figure 5). The HGL wetland system maintained most stabilized in these three kinds of wetland subsystem before 1996 (Figure 5), but thereafter, the condition turned worse, and the overall pattern changed significantly. Before 1995, the BLM wetland subsystem showed the different change trend from other two typical wetlands, and the deflection emerged during $1995 \sim 2000$.

\subsection{The Inherent Relevance between the Components and Overall Pattern Developments}

Landscape pattern evolution of wetland system is the concurrent result of each wetland component in the systems, but the influence of each component on overall landscape pattern is different in degree (Bai et al., 2005; Hu and Wang, 2007). Based on the class level, this paper employed index $C$ to evaluate the contribution of each component, and three components of each landscape index with the smallest $C$ value were selected out of all components for subsequent analysis (as listed in Table 3). In general, the landscape index in class level with more stable change will contribute more to the landscape pattern change of the overall wetland system.

The time series integrated index $C$ at land level representing pattern development of wetland system was selected as a dependent variable. Landscape indices at class level with stable time series change (see Table 3), representing the developments of components in system were selected as independent variables. The forward stepwise regression analysis method was used to build the casual relation between wetland landscape pattern and components (listed in Table 4). The variables accepted by regression equation were considered to have close relations with wetland-landscape pattern evolution.

It can be seen from Table 4 that by the way of mathematical statistics, some finite variables were selected from the initial 12 variables, which indicates that time series changes of selected components play a predominant part in the overall pattern development of regional wetland system. Obviously, the main components driving spatial pattern evolution in each typical wetland system are different from each other. It means the different forces for each component driving system development. The sequence of each component according to contribution is $x_{1}>x_{2}>x_{3}>\ldots$, it can be obtained that:

(1) In YRD wetland subsystem: Wetland components that influenced the spatial pattern development of YRD wetland system mainly are river, coastal marsh, tideland, and breeding pond (Table 4). Among them, river radically changes wetland spatial pattern of YRD because the river estuary is influenced by the variation of the sink of the Yellow River and causes frequent vibration of the lower reaches of Yellow River in delta (Huang et al., 2005). Except the interference of human disturbance, the change of coastal marsh is mainly hydrologic process change caused by the interaction of erosion and deposition mechanisms of the river estuary ( $\mathrm{Li}$ et al., 2009; Li et al., 2010b). Hydrological process then drives biochemical processes of vegetation development (Cui and Yang, 2006). Tideland is mainly influenced by the interaction between the river and sea (e.g., caused by change of Yellow River sink and marine erosion), besides, it is also influenced by storm surge (Zhang et al., 2006b). Breeding pond is a common kind of human-use landscape, which can reflect the artificial wetland increasing, as well as the natural wetland decreasing.

(2) In HGL wetland subsystem: The main components controlling the spatial pattern development of HGL wetland system are lake shoal, lake, inland, and artificial breeding pond (Table 4). Hongze-Gaoyou lakes play an important part in water storage, flood regulating and ecological function in the middle and low basin of Huaihe River ( $\mathrm{Li}$ and $\mathrm{Pu}, 2003$ ). The spatial pattern change in HGL wetland subsystem mainly is manifested as lake shoal and island appearing and subsiding caused by the water volume inpouring from upper reach and dam regulation and control (Hu et al., 2008). A large amount of lake reclamation landscapes (e.g., fish fence, shrimp and crab field, etc.) also change the wetland pattern obviously.

(3) In BLM wetland subsystem: The time series change of 
wetland components including valley flat, floating grass marsh, lake, reed marsh, reservoir and lotus pond landscape (Table 4), influences the spatial pattern evolution in BLM wetland subsystem significantly. Dominant landscapes in BLM wetland subsystem are reed field, lotus pond, float grass marsh and lake (open-water) (see Figure 2). The total area of BLM wetland substantially declined in 1970s (Figure 3). After that, the change is mainly manifested as spatial pattern development of each component inner the system, e.g., the lake body is divided by a variety of wetland landscapes and falls to pieces; Hydrobiological process caused by lake pondage variation resulted in spatial change of floating vegetation (Wang et al., 2008). Lotus pond is one kind of important regional artificial wetland landscape, whose changes influence the spatial pattern of wetland use.

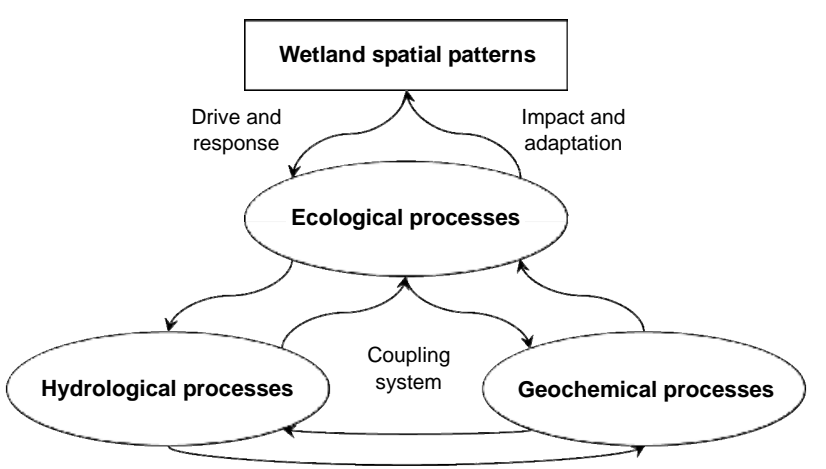

Figure 6. The relationship between wetland spatial patterns and processes.

\section{Discussions}

\subsection{About Landscape Indices and Entropy Index $C$}

Landscape index matrix has been successfully applied to study the landscape pattern and ecological process for various ecological systems ( $\mathrm{Li}$ et al., 2005). In the same way, this paper used the landscape indices to qualify the pattern of wetland system, and analyzed the ecological process by time series change of landscape indices. However, landscape index analysis is highly dependent on spatial scale and numbers of patches (Corry and Nassauer, 2005), which poses the uncertainty problem to landscape index analysis. Furthermore, spatial pattern evolution process of wetland system is closely linked with its ecological process by their coupling and interactive relationships, and the process mainly includes hydrologic, ecologic and biogeochemical cycles (Hu and Wang, 2007; Li et al., 2008b). This paper had made an analysis of the relationship between pattern and process from the view of landscape scale level, but left that of the small and molecular scale biogeochemical cycle process unmentioned.

More importantly, the current landscape indices developed by numerous literature are various, which means the analysis will be faced with a lot of information redundancy and uncertainty (Chen et al., 2008; Li et al., 2005), even some indices may lead to controversial results of ecologic signifycance (Chen et al., 2008; Corry and Nassauer, 2005). Cur- rently, there have been several works on how to select the indices rationally by comparing the different indices (Li et al., 2005), or how to build a new index by combing the existing landscape matrices (Bailey et al., 2007; Zhang et al., 2006a). Our work in this paper is to use the concept of information entropy to integrate the various landscape matrices. The analysis above shows the selected wetland components according to entropy index $C$ make significant contribution to the landscape pattern evolution, which made the analysis with clear logical and physical significances. Compared with our previous work ( $\mathrm{Li}$ et al., 2010a), the entropy $C$ led to the similar results, which also confirms the correct use of entropy in this paper.

\subsection{The Main Driving Forces for Pattern Developing in 3H Wetland Ecosystems}

(1) The severe anthropogenic disturbances are the most direct driving forces that promote the wetland system spatial pattern evolution in 3H Area.

The modern spatial pattern and its evolution in $3 \mathrm{H}$ Area have been driven by the synthetical forces of the continuously increases human activities and the creature succession caused by hydrological process like river-ocean and river-lake interaction (Han et al., 2006; Wang and Wang, 2007).

Land use is one of the most direct anthropogenic disturbances to natural ecosystem. Human use of wetland can change the spatial pattern of natural wetland directly. In the last 30 years, the urbanization, population growth and increasing press of food have caused a lot of wetland conversion into farmlands. For instance, according to the mapping result, the total 639.9 $\mathrm{km}^{2}$ natural wetlands were reclaimed in 3H Area during 1985 $\sim 2000$. The increase in farmlands (especial in paddy land) was bound to increase agricultural water use causing the regional shortage of water resource, which changed a lot of paddy field into dry land, e.g., $72.2 \mathrm{~km}^{2}$ paddy field was converted into dry land in YRD area during $1979 \sim 2005$. The reservoir and ponds also increased a lot in the whole $3 \mathrm{H}$ Area over the study period, such as the increase of $1,045.5 \mathrm{~km}^{2}$ in $3 \mathrm{H}$ Area during $1985 \sim 2000$, and $381.6 \mathrm{~km}^{2}$ in YRD area during $1979 \sim 2005$. The purpose of constructing a lot of reservoir is to enhance the ability of managing the limited water resource and reducing the risk of drought and flood disasters (Cummings and Winkelman, 1970). In addition, there are some wetland use types with volatility, which will cause the local wetland patterns unstable. For instance, the landscapes like fish fence around lakes, lotus pond and wetland attractions would be vulnerable to market uncertainties and other factors. Some special wetland usages also to some extend changed the pattern of local wetland ecosystem, such as oilfield and saltpan landscapes in YRD area.

The human activities that have direct impact on hydrological processes and ecological patterns of wetland ecosystems also include the construction of water conservancy facilities. For instance, the dike and dam construction in Huai River after 1950s blocked the good lateral flow connectivity between river channel and flood zone. It led to the disappea- 
rance of a large number of river branch and small lakes, therewith, a massive reclamation arose, which directly resulted in the wetland shrinkage ( $\mathrm{Hu}$ et al., 2008). Dam-building had also changed the hydrological process of the lower reaches, e.g., Bengbu sluice gate affected the hydrological regime downstream including Hongze-Gaoyou lakes, with the performance of stop event increasing, the duration of the average and peak flow declining, and had a great impact on wetland ecosystem patterns (Hu et al., 2008). On the other hand, dam also controlled the gate to the downstream water, and then regulated the hydrological process by the lake water level change in the HGL area. It also resulted in the landscape pattern change of the lake island and lake shoal with aquatic plants (Luo and Xie, 2009; Xie et al., 2008).

The pollution is another anthropogenic disturbance to wetland ecosystem. The rapid economic growth brought a large number of pollutants discharging into the wetland system. It caused series pollution and eutrophication, which finally changed the growth spatial patterns of aquatic plants, e.g., the areasource pollution in BLM ecosystem (Qin et al., 2009), and heavy metal pollution and oil pollution in YRD ecosystem (Nie et al., 2010) turned out to affect the growth pattern of wetland plants.

(2) Hydrological process dynamics cause hydro-ecological process changing, which is the internal mechanism of driving regional wetland ecosystem evolution.

The hydrological process changes of discharge and sediment caused the significant change in ecological process, resulting in the spatial-temporal pattern change in wetland ecosystems (Cai et al. 2011a; Li et al. 2010b). In the Yellow River Delta, the hydrological process was mainly a complicated flow and sediment process of river-sea interaction, and the delta's survival and growth depended upon the river sediment ( $\mathrm{Li}$ et al., 2009). The Yellow River rushed down with annually 1.6 billion tons of sediment, of which 0.4 billion tons deposited in the downstream flow path causing river bed silting up at a speed of $10 \sim 20 \mathrm{~cm}$ per year, and another 1.2 billion tons was delivered to the estuary area to form gigantic land delta and underwater delta (Xu, 2009). Besides building land, the continuous deposition of sediment a delta, which largely changed the evolution process of delta also led to frequent swing of Yellow River's sink at the wetland-landscape pattern. For example, in May 1976, the estuary was artificially diverted $150 \mathrm{~km}$ south from the Diaokou river path through which the Yellow River had been flowing for 12 years, and it merged into the Laizhou Bay from the Qingshuigou path. Here the estuary spit quickly spread southeast at a speed of $2.34 \mathrm{~km}$ per year. The estuary then moved $11 \mathrm{~km}$ northwest in 1996 and 2.28 km north until August 2007, naturally diverted into sea (Hou et al., 2009; Yin et al., 2004). Simultaneously after estuary diverted, the original estuary inordinately drew back due to reinforcing of marine erosion (Yin et al., 2004). Therefore, the Yellow River Delta wetland system pattern was greatly related to river path diversion.

Besides affecting the overall delta spatial pattern of new land formation, the water and sediment process also plays an important role in forming and maintaining the estuarine wetland system, and promoting ordinal succession of delta wetland ecological system. Since 1950s, the inflow rate and sediment into Yellow River Delta have shown stable decreasing trend (Li et al., 2009). The area of main wetland types showed close positive correlated to the runoff and sediment discharge, at a rate of $200 \sim 300 \times 10^{8} \mathrm{~m}^{3}$ and at $5 \sim 8 \times 10^{8} \mathrm{t}$, respectively, which were probably the most optimal range for maintaining the stable wetland landscape pattern ( $\mathrm{Li}$ et al., 2009). The mechanism mainly is that the hydrological process affects the geochemical process of wetland system, and the geochemical process affects the ecological process, and finally affects the spatial pattern of wetland vegetation (Figure 6). For instance, the Yellow River supply regulated the salt concentration of ground water (Li et al., 2008c), which had a significant impact on the distribution of plant communities (Li et al., 2009). Wetland soil nutrient movements like nitrogen mineralization and nitrifying process also were affected by the frequency of seasonal flooding of wetlands (Bai et al., 2007). Simultaneously, the soil salinity and nutrients as well as the light change caused by flooding depth all would significantly affect the seed germination of aquatic plants and spatial distribution of wetland vegetation (Cui et al., 2008a; Cui et al., 2008b; Xie et al., 2007). Because wetland vegetation has a certain ability of adapting and adjusting to hydrological and geochemical process of wetland ecosystems (Xie et al., 2007), wetland landscape pattern will evolve accordingly. On the other hand, the pattern of wetland vegetation also affects the water and soil geochemical cycle. Hydrological processes, geochemical processes and ecological processes influence each other to form a coupled system, and all adjust and adapt to the spatial pattern of wetland system and its evolution process (Figure 6). For example, wetlands under different flooding frequency in different vegetation communities had different soil $\mathrm{N}$ mineralization and nitrification processes (Bai et al., 2010; Xie et al., 2007); the flooding frequency also had an impact on reed litter (Xie et al., 2008).

Thus it can be seen, regulating the hydrological process of wetlands is one of the effective ways to restore the spatial patterns and function of wetland vegetation system. For instance, the run-off and sediment regulation works in Yellow River since 1999 has been regulated for the hydrological processes in the Yellow River Delta, causing the cutoff events of Yellow River declining significant, which has been playing a positive role in restoring the typical vegetation in wetland (Li et al., 2010b). Since the Year 2000, the flow rate of Lijin section has increased much, and the vegetation ecosystem of estuary area has greatly improved (He et al., 2007). The analysis in this paper also captures the inflection point occurring around 2001 in YRD environment (Figure 4). By 2005, the situation is basically restored to the level in 1996 (Figure 5), which is in consistent with the previous studies (Cui et al., 2009; Li et al., 2009).

(3) The climate change can aggravate the regional change processes of wetland pattern, and amplify the effect of changes.

The climate change can cause less regional precipitation and higher surface temperature, which would increase regional evaporation and water demand for natural service, amplifying the water press of regional economic development and the ef- 
fects of system hydrological processes. For instance, since the 1980s, the annual precipitation of the Yellow River basin has decreased sharply. Compared with the 1950s, the precipitation decreased by 50 percent, corresponding runoff lowered by 7 percent and 22 percent (Cui et al., 2006). Meanwhile with the economic development, the industrial and agricultural water consumption increased greatly, which aggravated water resource shortage in the basin and finally led to severe cutoff at downstream of the Yellow River. The decrease of Yellow River runoff resulted in large variation of estuary sediment, and accelerated shrinkage of delta freshwater wetland, and finally the Yellow River delta natural wetland presented a severe shrinkage status (He et al., 2007). The runoff and sediment decline in BLM was also to some extent related to the regional climate change. The work in BLM also can prove this view (Liu et al., 2006).

(4) The extraneous pressure such as natural disaster and alien invasive species may also be one of the reasons for driving the pattern change of wetlands.

Storm surge is a huge natural disaster from sea. It is often a destructive power to delta wetlands and changes their original ecosystem pattern by means of destructing beach morphology, causing or aggravating soil salinization in flooding area, or even destroying the dense vegetation into bare soil. For example, after the extreme storm surge in 1992, the area of artificial robinia pseudoacacia forest in the natural reserve in YRD decreased from $307.44 \mathrm{hm}^{2}$ to $176.85 \mathrm{hm}^{2}$ in 1993 , then to $110.34 \mathrm{hm}^{2}$ in 1995.

The extreme droughts can produce a large area of new flood plain and cause the original flood plains dry, resulting in the space mitigation of aquatic vegetation (Luo et al., 2008). On the contrary, the extreme floods can cause widespread flooding area, and produce a lot of wetland transition zones, which also can change the original wetland spatial patterns (Luo and Xie, 2009). All these natural weather disasters can cause a temporary change in wetland pattern, but they are not normal driving causes.

Additionally, the alien invasive species are also a potential driving force for wetland-vegetation pattern change, e.g., Spartina is a common alien invasive species in coastal areas in China. It has been reported to cause serious impact on salt marsh (Wu et al., 2009), which also to some extent changes the local patterns of wetland vegetation system.

\section{Summary}

In this paper, we used the remote sensed archive data to retrieve the wetland landscape spatial pattern and its recent 30 -year historical development in $3 \mathrm{H}$ Area in the central Northern China. The results show that the total area of wetlands in 2000 in $3 \mathrm{H}$ Area is approximate $32,632.9 \mathrm{~km}^{2}$, of which the natural wetland accounts for about 2.21 percent. In the past 30 years, the natural wetland decreased much in area, and the artificial wetlands presented a gradual increase, but the total area of wetlands was subjected to a decline trend. As three typical wetland sub-systems of hydro-network in the $3 \mathrm{H}$ Area, the YRD, HGL and BLM are subjected to similar deve- loping trends with an inflection point around 2000, and the trends are in consistence with the overall trend of whole $3 \mathrm{H}$ Area. However, the contribution of various components in each sub-system is very different in driving their own spatial pattern development. The ecological process of wetland system is mainly harmed by the increasing human disturbances that go beyond the reach of self-regulating of wetland system. Human disturbances have changed the spatial pattern of wetland components directly, while the changes of the hydrological, geochemical and ecological processes of wetland system also resulted in the evolution of landscape pattern. Climate change can aggravate the regional pattern change processes, and the extraneous pressures such as natural disaster and alien invasive species may be one of the driving forces. The study also indicates that it is necessary to regulate hydrological process in line with natural rules for the recovery and reconstruction of wetland system.

Acknowledgments. This research was supported jointly by the Hundred Talents Project and the Knowledge Innovation Program (No.KZCX2-YW-QN313) of the Chinese Academy of Sciences, the National Natural Science Foundation project of China (No.4127143 3), and the National Basic Research Program (973) of China (No. 2006CB403301) grant. We are grateful to the anonymous reviewers whose constructive suggestions have improved the quality of this paper.

\section{References}

Bai, J., Deng, W., Wang, Q., Cui, B., and Ding, Q. (2007). Spatial Distribution of Inorganic Nitrogen Contents of Marsh Soil in a River Floodplain with Different Flood Frequencies from Soil-Defrozen Period. Environ. Monit. Assess., 134(1-3), 421-428. http:// dx.doi.org/10.1007/s10661-007-9633-2

Bai, J., Gao, H., Deng, W., Yang, Z., Cui, B., and Xiao, R. (2010). Nitrification potential of marsh soils from two natural salinealkaline wetlands. Biol. Fert. Soils, 46(5), 525-529. http://dx.doi. org/10.1007/s00374-010-0441-4

Bai, J., Ouyang, H., Yang, Z., Cui, B., Cui, L., and Wang, Q. (2005). Changes in Wetland Landscape Patterns: a Review. Progr. Geogr., 24(4), 36-45.

Bailey, D., Herzog, F., Augenstein, I., Aviron, S., Billeter, R., Szerencsits, E., and Baudry, J. (2007). Thematic resolution matters: Indicators of landscape pattern for European agro-ecosystems. Ecol. Indic., 7(3), 692-709. http://dx.doi.org/10.1016/j.ecolind.200 6.08.001

Baird, A.J., Price, J.S., Roulet, N.T., and Heathwaite, A.L. (2004). Special Issue of Hydrological Processes Wetland Hydrology and Eco-Hydrology. Hydrol. Process., 18(2), 211-212. http://dx.doi. org/10.1002/hyp.1370

Bar-Ilan, J. (2008). Informetrics at the beginning of the 21st centuryA review. J. Inform., 2(1), 1-52. http://dx.doi.org/10.1016/j.joi.200 7.11.001

Brunsell, N.A. (2010). A multiscale information theory approach to assess spatial-temporal variability of daily precipitation. J. Hydrol., 385(1-4), 165-172. http://dx.doi.org/10.1016/j.jhydrol.2010.02.016

Bu, R., Hu, Y., Chang, Y., Li, X., and Hong, S.H. (2005). A correlation analysis on landscape metrics. Acta Ecol. Sin., 25 (10), 2764 -2775 .

Cai, Y.P., Huang, G.H., Tan, Q. and Chen, B. (2011a). Identification of optimal strategies for improving eco-resilience to floods in ecologically vulnerable regions of a wetland. Ecol. Model., 222, 
360-369. http://dx.doi.org/10.1016/j.ecolmodel.2009.12.012.

Cai, Y.P., Huang, G.H., Wang, X., Li, G.C. and Tan, Q. (2011b). An inexact programming approach for supporting ecologically sustainable water supply with the consideration of uncertain water demand by ecosystems. Stoch. Env. Res. Risk. A., 25, 721-735. http: //dx.doi.org/ 10.1007/s00477-011-0477-5.

Chen, L., Fu, B., and Zhao, W. (2006). Source-sink landscape theory and its ecological significance. Acta Ecol. Sin., 26(5), 1444 -1449.

Chen, L., Liu, Y., Lü, Y., Feng, X., and Fu, B. (2008). Pattern analysis in landscape ecology: progress, challenges and outlook. Acta Ecol. Sin., 28(11), 5521-5531. http://dx.doi.org/10.1016/S1 872-2032(09) 60011-1

Corry, R.C., and Nassauer, J.I. (2005). Limitations of using landscape pattern indices to evaluate the ecological consequences of alternative plans and designs. Landscape. Urban Plan., 72(4), 265-280. http://dx.doi.org/10.1016/j.landurbplan.2004.04.003

Costanza, R., dArge, R., deGroot, R., Farber, S., Grasso, M., Hannon, B., Limburg, K., Naeem, S., ONeill, R.V., Paruelo, J., Raskin, R.G., Sutton, P., and vandenBelt, M. (1997). The value of the world's ecosystem services and natural capital. Nature, 387(6630), 253260. http://dx.doi.org/10.1038/387253a0

Cui, B., Chang, X., Chen, Y., Dong, Q., and Li, W. (2006). The Impact of Hydrological Characteristics of the Yellow River Coastline Changes in the Yellow River Delta. J. Nat. Resour., 21(6), 957-964.

Cui, B., He, Q. and Zhao, X. (2008a). Ecological thresholds of Suaeda salsa to the environmental gradients of water table depth and soil salinity. Acta Ecol. Sin., 1408-1418.

Cui, B., Yang, Q., Yang, Z., and Zhang, K. (2009). Evaluating the ecological performance of wetland restoration in the Yellow River Delta, China. Ecol. Eng., 35(7), 1090-1103. http://dx.doi.org/10. 1016/j.ecoleng.2009.03.022

Cui, B., and Yang, Z. (2006). Wetlands, Beijing, Beijing Normal University Press.

Cui, B., Zhao, X., Yang, Z., Chen, B., Tang, N., and Tan, X. (2008b). Response of reed community to the environment gradient water depth in the Yellow River Delta, China. Frontiers of Biology in China, 3(2), 194-202. http://dx.doi.org/10.1007/s11515-008-0025-y

Cummings, R.G., and D.L.Winkelman (1970). Water Resource Management in Arid Environs. Water Resour. Res., 6(6), 1559-1568. http://dx.doi.org/10.1029/WR006i006p01559

David, P., and Thomas, P.V. (1998). Ecological scale: Theory and Application, New York: Columbia University Press.

Deng, W., Bai, J., Hu, J., and Li, A. (2010). Constructing a classification system of wetlands in Huang-Huai-Hai plain. Advances in Earth Science (in Chinese), 25(10), 1023-1029.

Deng, W., and Hu, J. (2003). Development of Wetland Hydrology Research and Key Scientific Issues. Wetland Science, 1(1), 12-20.

El Serafy, S. (1998). Pricing the invaluable: the value of the world's ecosystem services and natural capital. Ecol. Econ., 25(1), 25-27.

Gustafson, E.J. (1998). Quantifying landscape spatial pattern: What is the state of the art. Ecosystems, 1(2), 143-156. http://dx.doi.org/ $10.1007 / \mathrm{s} 100219900011$

Han, M., Zhang, X., and Liu, L. (2006). Research progress on wetland of the Yellow River Delta. Ecology and Environment, 15(4), 872-875.

He, C., Zhao, K., Yu, G., Zhao, Z., and Wang, G. (2000). Advance in Research of Ecological Processes in Wetland. Advance in Earth Sciences, 15(2), 165-171.

He, Q., Cui, B., Zhao, X., Fu, H., Xiong, X., and Feng, G. (2007). Vegetation Distribution Patterns to the Gradients of Water Depth and Soil Salinity in Wetlands of Yellow River Delta, China. Wetland Science, 5(3), 208-214.

Hocking, R.R. (1976). The Analysis and Selection of Variables in Linear Regression. Biometrics, 32(1), 1-49. http://dx.doi.org/10.23 $07 / 2529336$
Hou, Z., You, B., and Li, S. (2009). Erosion and deposition characteristic analysis of tail reaches in the Yellow River Estuary in recent years. J. Sediment Res., 1, 48-53.

Hu, W., and Wang, G. (2007). Advances in Research of Landscape Patterns and Ecological Processes of Wetland. Advances in Earth Science, 22(9), 969-975.

Hu, W., Wang, G., Deng, W., and Li, S. (2008). The influence of dams on eco-hydrological conditions in the Huaihe River basin, China. Ecol. Eng., 33(3-4), 233-241. http://dx.doi.org/10.1016/j.ecoleng. 2008.04.003

Huang, H., Li, F., and Pang, J. (2005). Study on land-ocean interaction in Yellow River Delta with Bohai Sea and Yellow Sea, Beijing, Science Press.

Huang, Y., Fu, B., and Chen, L. (2003). Advances in ecohydrological process research. Acta Ecol. Sin., 23(3), 580-587.

Jenssen, M. (2007). Ecological potentials of biodiversity modelled from information entropies: Plant species diversity of NorthCentral European forests as an example. Ecol. Inform., 2(4), 328-336. http://dx.doi.org/10.1016/j.ecoinf.2007.06.003

Lee, T., and Yeh, H. (2009). Applying remote sensing techniques to monitor shifting wetland vegetation: a case study of Danshui River Estuary mangrove communities, Taiwan. Ecol. Eng., 35(4), 487496. http://dx.doi.org/10.1016/j.ecoleng.2008.01.007

Li, A., Deng, W., Kong, B., Song, M., Feng, W., Lu, X., Lei, G., and Bai, J. (2010a). A comparative analysis on spatial patterns and processes of three typical wetland ecosystems in $3 \mathrm{H}$ area, China. Procedia Environmental Sciences, 01, 334-351.

$\mathrm{Li}, \mathrm{B}$., and Pu, P. (2003). Study on the evolution tendency of water quality in Huai River basin and Hongze Lake. Resources and Environment in the Yangtze Basin, 12(1), 67-73.

Li, S., Lu, H., Zhang, Y., Han, L., Yang, F., and Wu, C. (2008a). Spatial-Temporal Distribution Characteristics of Dryness/Wetness over Huanghuaihai Region from 1961 to 2006. Meteorological Science and Technology, 36(5), 601-605.

Li, S., Wang, G., and Deng, W. (2008b). Research advances in wetland landscape pattern and hydrological process. Chinese Journal of Ecology, 27(6), 1012-1020.

Li, S., Wang, G., Deng, W., and Hu, Y. (2009). Effects of runoff and sediment variation on landscape pattern in the Yellow River Delta of China. Advances in Water Science, 20(3), 325-331.

Li, S., Wang, G., Deng, W., Hu, Y., and Hu, W. (2010b). Influence of hydrology process on wetland landscape pattern: A case study in the Yellow River Delta. Ecol. Eng., 35(12), 1719-1726. http://dx. doi.org/10.1016/j.ecoleng.2009.07.009.

Li, S., Wang, G., Deng, W., and Lv, Y. (2008c). Variations of Groundwater Depth in Yellow River Delta in Recent Two Decades. Progress in Geography, 27(5), 49-56.

Li, X., Bu, R., Chang, Y., Hu, Y., Wen, Q., Wang, X., Xu, C., Li, Y., and He, H. (2004). The response of landscape metrics agaist pattern scenarios. Acta Ecol. Sin., 24(1), 123-134.

Li, X., He, H.S., Bu, R., Wen, Q., Chang, Y., Hu, Y. and Li, Y. (2005). The adequacy of different landscape metrics for various landscape patterns. Pattern Recogn., 38(12), 2626-2638. http://dx.doi.org/10. 1016/j.patcog.2005.05.009

Liu, C., Xie, G., and Huang, H. (2006). Shrinking and Drying up of Baiyangdian Lake Wetland: A Natural or Human Cause? Chinese Geogr. Sci., 16(4), 314-319. http://dx.doi.org/10.1007/s11769-0060314-9

Liu, H., Lu, X., and Zhang, S. (2003). Progress on the study of process of wetland Landscape changes and cumulative environmental effects. Progress in Geography, 22(1), 60-67.

Lu, Y.H., and Fu, B.J. (2001). Ecological scale and scaling. Acta Ecologica Sinica, 21(12), 2096-2105.

Luo, W., Song, F., and Xie, Y. (2008). Trade-off between tolerance to drought and tolerance to flooding in three wetland plants. Wetlands, 
28(3), 866-873. http://dx.doi.org/10.1672/07-225.1

Luo, W., and Xie, Y. (2009). Growth and morphological responses to water level and nutrient supply in three emergent macrophyte species. Hydrolobiologia, (624), 151-160.

Mishra, A.K., Özger, M., and Singh, V.P. (2009). An entropy-based investigation into the variability of precipitation. J. Hydrol., 370 (1-4), 139-154. http://dx.doi.org/10.1016/j.jhydrol.2009.03.006

Nie, M., Xie, N.X., Fu, X.H., Chen, X.F., and Li, B. (2010). The interactive effects of petroleum-hydrocarbon spillage and plan rhizosphere on concentrations and distribution of heavy metals in sediments in the Yellow River Delta, China. J. Hazard. Mater., 174 (1-3), 156-161. http://dx.doi.org/10.1016/j.jhazmat.2009.09.030

O'Neill, R.V., Krummel, J.R., Gardner, R.H., Sugihara, G., Jackson, B., DeAngelis, D.L., Milne, B.T., Turner, M.G., Zygmunt, B. Christensen, S.W., Dale, V.H. and Graham., R.L. (1988). Indices of landscape pattern. Landscape Ecol., 1(3), 153-162. http://dx.doi. org/10.1007/BF00162741

OECD (1996). Guidelines for aid agencies for improved conservation and sustainable use of tropical and subtropical wetlands, In. Paris, France: Organisation for Economic Co-operation and Development.

Qin, X.S., Huang, G.H., Chen, B. and Zhang, B.Y. (2009). An interval-parameter waste-load-allocation model for river water quality management under uncertainty. Environ. Manage., 43(6), 999-1012.

Scott, D.A., and Jones, T.A. (1995). Classification and inventory of wetlands: A global overview. Plant Ecol., 118(1-2), 3-16. http://dx. doi.org/10.1007/BF00045186

Shannon, C.E. (1948). A mathematical theory of communication. AT\&T Tech. J., 27, 370-423, 623-656.

Tang, X., and Huang, G. (2003). Study on Classification System for Wetland Types in China. Forest Research, 16, 531-539.

Tischendorf, L. (2001). Can landscape indices predict ecological processes consistently? Landscape Ecol., 16(3), 235-254. http://dx. doi.org/10.1023/A:1011112719782

Toman, M. (1998). Why not to calculate the value of the world's ecosystem services and natural capital. Ecol. Econ., 25(1), 57-60. http://dx.doi.org/10.1016/S0921-8009(98)00017-2

Turner, M.G. (1990). Spatial and temporal analysis of landscape patterns. Landscape Ecol., 4(1), 21-30. http://dx.doi.org/10.1007/ BF02573948

Turner, M.G., and Gardner, R.H. (Eds.) (1991). Quantitative methods in landscape ecology, New York, Springer-Verlag. http://dx.doi. org/10.1007/978-1-4757-4244-2
Wang, G., Qian, J., and Cheng, G. (2001). Present research and prospect in ecohydrology. Advances in Earth Science, 16(3), 314323.

Wang, Q., Liu, J., and Yang, Z. (2008). Environmental water demand of Baiyangdian Lake at different times and places. Acta Scientiae Circumstantiae, 28(7), 1447-1454.

Wang, Z., and Wang, G. (2007). Health assessment index system of Hongze Lake wetland ecosystem. Chinese Journal of Eco-Agriculture, 15(6), 152-155.

Wu, J. (2000). Landscape Ecology-Pattern,Process, Scale and Hierarchy, Beijing, Advanced Education Press.

Wu, Y.T., Wang, C.H., Zhang, X.D., Zhao, B., Jiang, L.F., Chen, J.K., and $\mathrm{Li}, \mathrm{B}$. (2009). Effects of saltmarsh invasion by Spartina alteriflora on arthropod community structure and diets. Biol. Invasion, 11(3), 635-649. http://dx.doi.org/10.1007/s10530-0089279-1

Xie, Y., Luo, W., and Ren, B. (2007). Morphological and physicological responses to sediment type and light availability in roots of the submerged plant Myriophyllum spicatum. Ann. Bot., 100(7), 1517-1523. http://dx.doi.org/10.1093/aob/mcm236

Xie, Y., Luo, W., Wang, K., and Ren, B. (2008). Root growth dynamics of the marsh plant Deyuexia angustifolia in response to water level. Aquatic Bot., 89(3), 292-296. http://dx.doi.org/10.1016/j.aqu abot.2008.03.003

Xu, D. (2009). Chang the route of Yellow River, Protect the East China Sea. http://www.sciencenet.cn/m/Print.aspx?id=225617.

Yang, Y. (2002). New knowledge on the progress of international wetland science research and priority field and prospect of Chinese wetland science research. Advance in Earth Sciences, 17(4), 508514.

Yang, Z., Cui, B., Huang, G., Bai, J., Sun, T., Li, X., and Liu, X. (2006). Hydro-ecological processes, Water-environmental Effects and Integrated Control of Ecological Security for Wetlands in Huang-Huai-Huai Region of China. Advances in Earth Science, 21(11), 1119-1126

Yin, Y., Zhou, Y., and Ding, D. (2004). Evolution of Modern Yellow River Delt Coast. Marine Science Bulletin, 23(2), 32-40

Zhang, S., Zhang, J., Li, F., and Cropp, R. (2006a). Vector analysis theory on landscape pattern (VATLP). Ecol. Model., 193(3-4), 492-502. http://dx.doi.org/10.1016/j.ecolmodel.2005.08.022

Zhang, X., Li, P., and Liu, Y. (2006b). Storm surge disaster and its impact on coastal wetlands in Yellow River Delta. Journal of Natural Disasters, 15(2), 10-13. 